TARRACONENSES AND «HisPANI/-AE TARRACONENSES».

CIVIC AND PROVINCIAL EPIGRAPHIC MEMORY IN COLONIA

IVLIA VRBS TRIVMPHALIS TARRACO

\title{
Tarraconenses e
}

«Hispani/-ae Tarraconenses».

En torno a la memoria epigráfica

cívica y provincial en la colonia

Iulia Vrbs Triumphalis Tarraco

Estíbaliz Ortiz-de-Urbina*

Universidad del País Vasco-Euskal Herriko Unibertsitatea

estibaliz.ortizdeurbina@ehu.eus

Fecha recepción 22.02.2016 / Fecha aceptación 22.06.2016

\section{Resumen}

La información aportada por el corpus epigráfico de Tarraco, colonia romana, capital de la extensa provincia Hispania citerior y primera sede de un emperador fuera de Roma, nos permite observar los procesos de integración política que estaban experimentado en época imperial sus cives, así como las comunidades cívicas ads-

\begin{abstract}
The information provided by the epigraphic corpus from Tarraco - a Roman colonia, capital of the vast provincia Hispania citerior and the first seat of an Emperor outside Rome - allows us to observe the political integration processes implemented during the Imperial period by its cives and the civic communities attached to its
\end{abstract}

\footnotetext{
* El desarrollo de esta contribución fue iniciado dentro del Proyecto de I+D HAR2011-27431/HIST (MICINN). Su conclusión se enmarca dentro del Proyecto de I+D del Programa Estatal de Fomento de la Investigación Científica y Técnica de Excelencia (HAR2015-65526-P (MINECO/FEDER). Asimismo, debe insertarse en la actividad efectuada por el Grupo de Investigación Reconocido del Sistema Universitario Vasco (IT 760-13).
} 


\section{Resumen}

critas a su administración provincial. En esta contribución analizamos estos procesos a partir de las referencias relativas a Tarraconenses e «Hispani/-ae Tarraconenses» aportadas por 73 inscripciones de este corpus epigráfico y 5 evidencias externas, con mención de la procedencia cívica (origo) y/o conventual (ex conventu), de la residencia o domicilio (domus), o del lugar de nacimiento (natio).

\section{Palabras clave}

Tarraco, epigrafía, Tarraconenses, «Hispani/-ae Tarraconenses», integración política, época imperial.

\section{Abstract}

provincial administration. This paper analyses these processes using sources concerning $\mathrm{Ta}$ rraconenses and "Hispani/-ae Tarraconenses», specifically 73 inscriptions from this epigraphic corpus and 5 external documents, with reference to civic origin (origo) and/or conventus of provenance (ex conventu), residence or domicile (domus), or place of birth (natio).

\section{Key words:}

Tarraco, epigraphy, Tarraconenses, «Hispani/-ae Tarraconenses», political integration, Imperial period. 
En la ciudad romana de Tarraco (Tarragona) convergen diferentes características históricas y documentales que la hacen singular desde una perspectiva del estudio del desarrollo y de la representación del poder romano en Hispania. Entre otras consideraciones de esta singularidad estarían: su temprana fundación romana; su localización y función estratégica en los procesos de conquista y romanización del ámbito peninsular; su condición de sede administrativa de Hispania citerior, la más diversificada - desde una perspectiva históricocultural- de las provinciae hispanas y extensa del Imperio romano; así como el amplio aporte documental de que disponemos actualmente sobre su configuración cívica e institucional, organización socio-económica, estructuración urbana y proyección provincial. En particular, se registra el corpus epigráfico más extenso del conservado entre las ciudades hispanas, disponible desde el último tercio del siglo pasado y revisado y actualizado en los últimos tres años por G. Alföldy ${ }^{1}$, quien se refería a esta colonia como «la primera sede de un emperador fuera de Roma», considerando la estancia de Augusto durante el desarrollo de las guerras cántabro-astures. Esta singularidad histórica y documental permite examinar esta «ciudad

1. G. Alföldy (Ed.), Corpus Inscriptionum Latinarum. Inscriptiones Hispaniae Latinae, editio altera. Pars XIV: Conventus Tarraconensis (CIL II²/14). Fasc. secundus. Colonia Iulia Vrbs Triumphalis Tarraco, BeroliniNovi Eboraci 2011; ID. (Ed.), CIL II²/14. Fasc. tertius. Colonia Iulia Vrbs Triumphalis Tarraco, BeroliniNovi Eboraci 2012. A estos dos corpora dedicados a la colonia se suma el dedicado al área meridional del conventus Tarraconensis: G. Alföldy, M. Clauss, M. Mayer (Eds.), CIL II ${ }^{2} / 14$. Fasc. primus. Pars meridionalis conventus Tarraconensis, Berolini-Novi Eboraci 1995. Sobre el territorio tarraconense, cf. D. Gorostidi, Ager Tarraconensis 3. Les inscripcions romanes (IRAT), Tarragona 2010. Cf. también G. Alföldy, "Las inscripciones de Tárraco en el Corpus Inscriptionum Latinarum: historia, problemas y perspectiva de una edición epigráfica", Butlletí Arqueològic, 28, 2006, 75-95; D. Gorostidi, "Géza Alföldy y las inscripciones romanas de Tarraco (1975-2011): novedades y nuevas perspectivas”, en J. López i Vilar (Coord.), Tarraco Biennal: Actes $1^{e r}$ Congrés Internacional d'Arqueologia i Món Antic: Govern i Societat a la Hispània Romana: Novetats epigràfiques. Homenatge a Géza Alföldy (Tarragona, 29-30 de novembre i 1 de desembre de 2012), Tarragona 2013, 135-143. 
del poder» desde diferentes perspectivas históricas, en las que son esenciales, asimismo, las notables investigaciones arqueológicas desarrolladas en las últimas tres décadas ${ }^{2}$.

La referencia a Tarraco como creación de los Escipiones queda precisada en las obras disponibles de diferentes autores clásicos a lo largo de finales de la República y del Principado, refiriéndose en algunos casos, asimismo, a su condición de colonia $a^{3}$ y, en autores tardíos, de caput provinciae $e^{4}$. Esta expresión parece transmitir, en particular, su idoneidad para la estancia - a la que alude Estrabón ${ }^{5}$ - y residencia del gobernador provincial en el praetorium consularis ${ }^{6}$; su condición de sede de un amplio número de instituciones estatales representativas del dominio romano en Hispania citerior y de los voluminosos archivos que su actividad generó; así como su función como centro de reunión del concilium provinciae integrado por representantes de las diferentes civitates adscritas. Estas cualidades de Tarraco no excluirían la presencia del gobernador provincial y el desarrollo de sus atribuciones o de aquellas que competen a sus colaboradores en otros centros de la provincia durante ciertos periodos del

2. Entre otras contribuciones, $c f$. J. Ruiz de Arbulo, "Edificios públicos, poder imperial y evolución de las élites urbanas en Tarraco (s. II-IV d.C.)", en J. Arce, P. Le Roux (Eds.), Ciudad y comunidad cívica en Hispania. Siglos II y III d.C. Actes du colloque: Madrid, $25-27$ janvier 1990, Madrid 1993, 93-113; ID., "Tarraco. Escenografía del poder, administración y justicia en una capital provincial romana (s. II a.C.-II d.C.)", Empúries, 51, 1998, 31-61; ID., "El altar y el templo de Augusto en la colonia Tarraco. Estado de la cuestión", en J. M. Noguera (Ed.), Fora Hispaniae. Paisaje urbano, arquitectura programas decorativos y culto imperial en los foros de las ciudades hispanorromanas, Murcia 2009, 155-189; J. M. Noguera, R. Mar, J. Domingo, I. Fiz, "Etapas y elementos de la decoración arquitectónica en el desarrollo monumental de la ciudad de Tarraco (s. II a.C.-I d.C.)", en S. Ramallo (Coord.), La decoración arquitectónica en las ciudades romanas de Occidente: Actas del Congreso Internacional celebrado en Cartagena (8 y 10 de octubre de 2003), Murcia 2004, 115-152; X. Dupré (Ed.), Las capitales provinciales de Hispania 3. Tarragona. Colonia Iulia Vrbs Triumphalis Tarraco, Roma 2004; R. Mar, J. Ruiz de Arbulo, D. Vivó, "El foro de la colonia Tarraco entre la República y el Imperio", en R. González Villaescusa (Coord.), Simulacra Romae II: Rome, les capitales de province (capita provinciarum) et la création d'un espace commun européen: une approche arhéologique, Reims 2010, 39-70.

3. Plin. NH. 3.21: colonia Tarracon Scipionum opus. Sobre este fragmento y la información proporcionada por otros autores greco-latinos (en particular, Polibio, Livio, Estrabón, Mela, Tácito, Apiano, Avieno, Ausonio) en relación con el inicio del proceso de conquista romana en el ámbito peninsular, la presencia

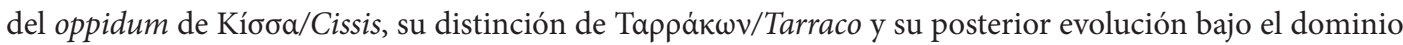
romano, cf. P. Otiña, J. Ruiz de Arbulo, "De Cese a Tárraco. Evidencias y reflexiones sobre la Tarragona ibérica y el proceso de romanización", Empúries, 52, 2000, 107-136.

4. Como lo indican el geógrafo y compilador latino C. Julio Solino en De mirabilibus mundi 23: Carthaginem apud Hiberos, quae mox colonia facta est, Poeni condiderunt, Tarraconem Scipiones: ideo caput est provinciae Tarraconensis; e Isidoro de Sevilla en Etymologiae 15.1.65: Terraconam in Hispania Scipiones construxerunt: ideo caput est Terraconensis provinciae.

5. Estrabón se refiere (3.4.7) a su condición «especialmente adecuada para las estancias de los gobernadores»; cf. trad. J. Gómez Espelosín, Geografía de Iberia. Estrabón, Madrid 2006, 240.

6. CIL II²/14.2, 837: c. 198-208/209 d.C.: ... Genio praetorii consularis... T(itus) Fl(avius) Titianus leg(atus) Augg(ustorum) pr(o) pr(aetore) Postumia Varia eius dicaverunt. 
año ${ }^{7}$. No obstante, la expresión caput provinciae es excepcional en la documentación grecolatina y parece no remitir, como se ha propuesto, a una terminología oficial de Tarraco o de otros centros político-administrativos representativos del gobierno provincial romano, que por otra parte documentan una gran diversidad de tipologías, circunstancias y procesos históricos específicos que en su conjunto - incluida su condición de capital provincial-contribuirían a su prestigio local $^{8}$.

\section{Colonia Tarracon Scipionum opus}

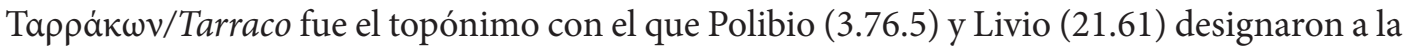
parte alta de una colina litoral localizada en la margen izquierda y proximidades de la desembocadura del antiguo Tulcis flumen, actual Francolí. En el año 218 a.C. las tropas romanas, al mando de Gn. Cornelio Escipión, establecieron en esta zona un campamento militar, creado

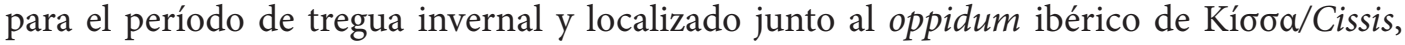
que se situaba en la parte baja de la misma colina ${ }^{9}$. Tanto el establecimiento de este inicial campamento militar como la posterior función de capital provincial de Tarraco, concluida la Segunda Guerra Púnica, no permiten argumentar de forma segura para algunos investigadores la existencia de un praesidium romano estable con una prolongada coexistencia al lado del oppidum indígena ${ }^{10}$. No obstante, la dinámica de transformaciones socio-económicas y urbanas que se evidencian en el oppidum ibérico bajo el dominio romano no debió de ser ajena a la condición de centro administrativo provincial de Tarraco a partir del 197 a.C., lugar de tránsito de las legiones destacadas y foco de atracción de emigrantes romano-itálicos ${ }^{11}$.

Acuñaciones de plata y bronce del siglo II y primer cuarto del siglo I a.C. - con leyendas $\mathrm{Kese}$ y $\mathrm{Ke}(e) s(s)$ e en alfabeto ibérico ${ }^{12}$ — han sido puestas en relación con el desarrollo de una civitas, con un probable estatuto peregrino. Desde finales del s. II a.C. destacan, entre otras transformaciones urbanas, una planificación viaria ortogonal y un área pública de carácter monumental ${ }^{13}$. De este conjunto monumental procede la primera conmemoración pública tarraconense documentada en la actualidad, una dedicación a Pompeyo del 71 a.C. (CIL II $\left.{ }^{2} / 14.2,991\right)$, que pone de relieve el reconocimiento a quien entre el 77-72

7. R. Haensch, Capita provinciarum: Statthaltersitze und Provinzialverwaltung in der römischen Kaiserzeit, Mainz am Rhein 1997, 162-175, 480-489.

8. R. Haensch, “Types of provincial capitals", en J. Santos, E. Torregaray (Eds.), Laudes provinciarum: Retórica y política en la representación del imperio romano, Vitoria-Gasteiz 2007, 265-276.

9. Polib. 3.76.5; Liv. 21.60-61; cf. Otiña, Ruiz de Arbulo, loc. cit., 108-109.

10. F. Cadiou, Hibera in terra miles: les armées romaines et la conquête de l' Hispanie sous la République, 218-45 a.C., Madrid 2008, 340-344.

11. Cadiou, op. cit., 342; P. Le Roux, Romanos de España. Ciudades y política en las provincias (siglo II a.C.-siglo III d.C.), Barcelona 2006, 49-51 (1 $1^{\text {a }}$ ed. París 1995).

12. Ma P. García-Bellido, C. Blázquez, Diccionario de cecas y pueblos hispánicos II: Catálogo de cecas y pueblos, CSIC, Madrid 2001, 240-251.

13. Mar, Ruiz de Arbulo, Vivó, loc. cit., 2010, 39-40, 50. 
a.C. había ejercido el proconsulado en Hispania citerior $^{14}$. Por otra parte, las actividades económicas -en particular las de carácter comercial- propiciarían la presencia de inmigrantes itálicos en la zona, quizá organizados en asociaciones de tipo colegial presididas por magistri $\left(C I L \mathrm{II}^{2} / 14.3,1200\right)^{15}$.

Las investigaciones más recientes ${ }^{16}$ relacionan la fundación de la colonia de Tarraco con una deductio de veteranos leales a César, desarrollada con posterioridad a su muerte (44 a.C.), en un período en torno o coincidente con el gobierno (39-37 a.C.) de Gn. Domitius Calvinus en Hispania citerior. Esta nueva definición política implicó un cambio del recorrido cívico y administrativo de la comunidad establecida en la colina litoral. Además de la condición cívica como Tarraconenses de quienes fueron desde entonces habitantes de pleno derecho de la colonia, acreditaron asimismo la condición de cives Romani, un estatuto personal avalado desde instancias estatales, y se organizaron con los iura e instituciones del populus Romanus, siendo quasi effigies parva simulacrumque de Roma, si tenemos en cuenta la acepción de colonia ${ }^{17}$. El prefecto encargado por César de la fundación de la colonia pudo ser el senador P. Mucio Escévola, como se ha propuesto, quien fue conmemorado probablemente en los años 45-44 a.C. en la parte posterior de la lápida opistógrafa (CIL II $\left.{ }^{2} / 14.2,988\right)$ que había servido de soporte a la dedicación de Pompeyo en el 71 a.C., una reutilización que parece poner de relieve la supeditación de la colonia a las directrices estatales tras las victorias de César en Hispania ${ }^{18}$.

La documentación arqueológica y epigráfica revela las transformaciones institucionales y urbanas inherentes a la nueva constitución jurídica y política conferidas por Roma. A mediados del siglo I a.C. se remodeló y amplió la inicial área pública de carácter monumental y, en torno al cambio de era, se inició en el nuevo foro de la colonia la primera fase constructiva de una basílica ${ }^{19}$, sede de las actividades de los duunviros registrados en la epigrafía local, así como de otras magistraturas e instituciones de la colonia. Del interior de esta basílica forense proceden más de una decena de pedestales estatuarios, una pequeña parte de los que debieron de estar dispuestos durante la utilización del edificio - que concluye en el

14. CIL II'/14.2, 991: [Cn(aeo) Po]mpei[o Cn(aei)f(ilio) M]agn(o) im[p(eratori) iter(um)].

15. CIL II ${ }^{2} / 14.3$, 1200: [---] l(ibertus) Ephes[ius ---?][---]s mag(istri) [---]. Cf. B. Díaz Ariño, "Heisce Magistreis: aproximación a los collegia de la Hispania republicana a través de sus paralelos italianos y delios", Gerión, 22.2, 2004, 447-478, cit. 469.

16. J. Ruiz de Arbulo, "La fundación de la colonia Tarraco y los estandartes de César" en A. Ribera y J. L. Jiménez Salvador (Coord.), Valencia y las primeras ciudades romanas de Hispania, Valencia 2002, 137-156; ID., "La legión de Marte y la fundación de la colonia Tarraco", en J. López i Vilar (Coord.), loc.cit., 2013, 263-277, cit. 271-274.

17. Transmitida en época imperial por el lexicógrafo Aulo Gelio, NA 16.13.8.

18. CIL II²/14.2, 988: P(ublio) Mucio [P(ubli)? f(ilio)] Scaevol[ae]. Cf. R. Mar, J. Ruiz de Arbulo, D. Vivó, loc. cit., 2010, 45.

19. Cf. el análisis arqueológico relativo a las fases urbanísticas del foro de la colonia y de edificación de la basílica con pórtico anexo (chalcidicum) hasta época de Adriano, Mar, Ruiz de Arbulo, Vivó, loc. cit., 2010, 50-65. 
siglo IV_, relativos a homenajes dedicados a miembros de la domus Caesaris y a destacados protagonistas de la colonia y sede administrativa de la Citerior.

Entre las columnas de la basílica del foro de la colonia se localizó el primer homenaje estatuario que conmemora la plena integración de un tarraconense en las estructuras organizativas provincial y estatal e ideológica imperial. Se trata del pedestal (CIL II $\left.{ }^{2} / 14.2,992\right)$ dedicado entre los años c. 78-79 d.C., a expensas privadas, a [R]aecius Gallus, uno de los primeros flámines provinciales documentados en Hispania citerior, promovido desde el orden ecuestre al senatorial por Vespasiano, y nombrado previamente por el ordo de la colonia flamen perpetuo de este emperador flavio ${ }^{20}$. Además, en esta basílica, en el pórtico lateral anexo y en el área forense adyacente es donde se concentran, iniciado el Principado, evidencias significativas de la trascendencia del poder e ideología imperial. Entre otros testimonios arquitectónicos, escultóricos y epigráficos, destacan: representaciones alegóricas del dominio de Roma sobre diferentes provinciales; dedicaciones a la [Vi]ctor[ia] [A] ugusta (CIL II ${ }^{2} / 14.2$, 864) y a emperadores y miembros de la dinastía Julio-Claudia (CIL $\mathrm{II}^{2} / 14.2,883$ y 884$)$ a expensas de la colonia; restos escultóricos de un ciclo icónico imperial de esta primera dinastía imperial; tábulas marmóreas en honor de dos emperadores pertenecientes a los Flavios e Ilirios (CIL II²/14.2, 897 y 928); dedicaciones de los seviri Augustales a emperadores de las dinastías Antonina y Severa $\left(C I L I^{2} / 14.2,912 \text { y } 922\right)^{21}$.

20. Su pedestal conmemorativo corresponde a una dedicación privada de su amigo M(arcus) Minatius (CIL II²/14, 992: [- R]aecio Tauri [fil(io) G]al(eria) Gallo [trib(uno)] mil(itum) Galb(ae) Imp(eratoris) [fla]m(ini) Imp(eratoris) Vesp(asiani) Caes(aris) [Au]g(usti) perpetuo ex d(ecreto) d(ecurionum) [fl]am(ini) p(rovinciae) H(ispaniae) c(iterioris) quaestori provinc(iae) Bae[ticae] [t]rib(uno) pleb(is) prae[tori] sodali Augu[stali] M(arcus) Minatius [---] optimo et prae[stantis]simo amico). La disposición de este homenaje privado fuera de la plaza de representación, localizada en la parte alta de la colina tarraconense y donde se disponían las conmemoraciones oficiales concedidas por el concilium provinciae, no requirió la previa autorización de esta asamblea provincial. Cf. G. Alföldy, "Sociedad y epigrafía en Tarraco", en S. Armani, B. Hurlet-Martineau, A. U. Stylow (Eds.), Epigrafía y sociedad en Hispania durante el Alto Imperio: estructuras y relaciones sociales. Actas de la Mesa Redonda organizada por la Casa de Velázquez, el Centro CIL II de la Universidad de Alcalá y L' Année Épigraphique (Madrid-Alcalá de Henares, 10-11 de abril de 2000), Alcalá de Henares 2003, 159-176, cit. 165-166; D. Fishwick, The imperial cult in the Latin West: sudies in the ruler cult of the western provinces of the Roman Empire. III: Provincial cult. 2: The provincial priesthood, Leiden 2002, 101-104.

21. Mar, Ruiz de Arbulo, Vivó, loc.cit., 45-46, 58-62; CIL II ${ }^{2} 14.2$, 864: [Vi]ctor[iae][A]ugustae [colon]ia Triu[mphalis Tarrac(onensium)]; CIL II²/14.2, 883 (Tiberio o Claudio): Ti(berio) C(aesaris ?); CIL II²/14.2, 884 (Druso: 15-20 d.C.): [Druso Caesari] [Ti(berii) Aug(usti) f(ilio) Divi] Aug(usti) n(epoti) [Divi Iuli pr]onepoti [pon]tifici co(n)s(uli) [coloni]a Triumphal(is); CIL II²/14.2, 897 (Tito: $72-73$ d.C.): T(ito) Caes(ari) [Aug(usti) f(ilio) Vespasiano] imp(eratori) IIII [tribunicia potestate II] co(n)s(uli) II de[signat(o) III censori]; CIL II $/ 14.2,928$ (Probo: 276-282 d.C.): [Im]p(eratori) Caes(ari) M(arco) A[urelio] [Pro]bo Pio Fe[lici Aug(usto)] [p(ontifici) m(aximo) t]rib(unicia) pot(estate); CIL II²/14.2, 912 (Cómodo: c. 186 d.C.): Imp(eratori) Caesari M(arco) [Aurelio] Commodo An[tonino] Pio Felici Sa[rmatico] Germanico m[aximo Bri]tan(n)ico p(ontifici) m(aximo) t[rib(unicia) p(otestate) XI] imp(eratori) VII co(n)s(uli) V [patri patriae] sevir[i Augustales]; CIL II²/14.2, 922 (Severo Alejandro: 222-235 d.C.): [Imp(eratori) Caesari] M(arco) 
Por otra parte, en la zona más elevada de la colina tarraconense, donde se estableció la inicial base militar romana en época de los Escipiones, se documenta en época Flavia un conjunto arquitectónico con tres recintos diferenciados y localizados a diferentes alturas, coincidiendo con la regulación del culto imperial en el ámbito provincial y las reuniones anuales del concilium provinciae. La parte superior albergó un área sacra en torno a un templo con una aedes monumental, con estatuas dedicadas a los emperadores divinizados y a su ámbito familiar. Entre esta plaza sacra y el circo localizado en posición inferior se encontraba una plaza de amplias dimensiones, destinada a la representación de la élite provincial, receptora de los homenajes oficiales de los delegados provinciales o de aquellos autorizados por el concilio para su disposición en este recinto ${ }^{22}$. El primero de estos homenajes oficiales documentado (CIL $\left.\mathrm{II}^{2} / 14.2,1110\right)$ es el dedicado en época de Vespasiano (c. 70-75) a un provincial, perteneciente al ordo equester y flamen en el concilio, C. Aemilius Fratern [us], procedente de una familia de Aeso (Isona), localizada en el conventus Tarraconensis. La estructuración y monumentalidad de este complejo edilicio transmitía una clara manifestación de la influencia y del poder económico de los selectos «Hispani Tarraconenses» reunidos en el concilio provincial y de su adhesión al poder imperial y a la diosa $R o m a^{23}$. Pero, asimismo, el hecho de que los modelos arquitectónicos, estatuarios e iconográficos oficiales empleados mostraran una clara dependencia de los de la propia $V r b s$, no dejaba de ser una óptima vía de difusión de la sistematización e ideología política romana en la colonia y sede administrativa de Hispania citerior ${ }^{24}$.

\section{En torno a la memoria epigráfica cívica y provincial}

La documentación epigráfica hallada en la urbs, donde se concentran las evidencias relativas a la gestión local, y en el ager Tarraconensis, donde se localizaron las villae y los fundi de quienes se situaron al frente de la vida política de la colonia, revela en época imperial -hasta

[Aur(elio) Severo] Al[exandro] Pio [Felici Aug(usto)] Div[i Antonini f(ilio)] Div[i Severi nep(oti) p(ontifici) $m$ (aximo)] trib(unicia) p[ot(estate) --- co(n)s(uli) --- p(atri) p(atriae)] sev[iri Aug(ustales)].

22. Cf. supra n. 2; D. Fishwick, op. cit., 2002, 43-52, 95-170; I. Rodà, "Espacios de representación en los foros de Hispania", en J. M. Noguera (Ed.), loc. cit., 2009, 69-87, cit. 73-74; R. Mar, J. Ruiz de Arbulo, D. Vivó, "Los genios de los conventus iuridici y el lugar de reuniones del concilium provinciae Hispaniae citerioris. ¿Una 'curia' de uso provincial en Tarraco?', en B. Soler et alii (Eds.), Las sedes de los ordines decurionum en Hispania. Análisis arquitectónico y modelo tipológico, Mérida 2013, 25-41, cit. 27-35. En esta última contribución, junto a la propuesta de situar el templo de Augusto citado por Tácito (Ann., 1.78) en la plaza superior del que designan como «foro provincial» de Tarraco, se refieren los autores a la construcción en época Flavia de una nueva área sacra de mayor amplitud, con una gran aedes axial, entre cuyas funciones sugieren que pudo encontrarse la de ser empleada como uno de los espacios de reunión del concilium provinciae.

23. G. Alföldy, "Tarraco y la Hispania romana: cultos y sociedad", en M. Mayer (Ed.), Religio Deorum. Actas del Coloquio Internacional de Epigrafía: Culto y Sociedad en Occidente (Tarragona, 6-8 de octubre de 1988), Barcelona 1992, 7-26, cit. 20-21; ID., "Tausend Jahre epigraphische Kultur im römischen Hispanien: inschriften, selbstdarstellung und sozialordnung", Lucentum, 30, 2011, 187-220; cit. 201-202, 208.

24. Ruiz de Arbulo, loc. cit., 1993, 97-104; ID., loc. cit., 1998, 48-57; X. Aquilué, "Arquitectura oficial", en Dupré (Ed.), loc. cit., 41-53; Fishwick, op. cit., 2002, 5-40. 
mediados del siglo III- la proyección cívica y provincial de esta fundación romana y de quienes la habitaron, formando parte de sus habitantes de pleno derecho o no. Entre las referencias que aluden a los primeros, asociados a expresiones de carácter jurídico, político y/o institucional, destacan las menciones: cives Tarrac(onenses) (CIL II $2 / 14.2,1177)$; colonia Iulia Vrbs Triumphalis Tarr(aconensium) [o Tarrac(onensium)] (CIL II²/14.2, 819, 904, 920); colonia Tarr(aconensium) (CIL II $2 / 14.2,1124)$; aedilis, quaestores y IIviri de la colonia Iulia Vrbs Triumphalis T(arraconensium) [o Tarrac(onensium)] (CIL II $2 / 14.2,1017,1172)$; ordo decurionum u ordo Tarrac(onensium) [o Tarracon(ensium) y Tarraconens(ium)] (CIL II ${ }^{2} / 14.2$, 924, 973, 1005, 1139; CIL II²/14.3, 1203); decretum ordinis coloniae Tarracon(ensium) (CIL $\left.\mathrm{II}^{2} / 14.3,1209\right)$; decretum decurionum Tarr(aconensium) (CIL II $\left.2 / 14.3,1210\right)$; flamen de la colonia Iulia Vrbs Triumphalis T(arraconensium) (CIL II²/14.2, 1017); flaminica perpetua de la colonia Tarrac(onensium) (CIL II $\left.{ }^{2} / 14.2,1179\right)$. En estas evidencias epigráficas, en las que destaca la denominación oficial, se repite la referencia a los ciudadanos de Tarraco — también ciudadanos de Roma (cives Romani) - poniendo de relieve a quienes hacían posible la existencia de la colonia a través de su consenso en los asuntos de interés común, en clara sintonía con las observaciones ciceronianas (De re publica 1.25-26).

Algunos de estos ciudadanos, que integraron el populus tarraconense, tuvieron asimismo una memoria epigráfica concreta, como materializa la mención de su condición de Tarraconenses en las secuencias onomásticas con las que fueron designados en inscripciones honoríficas. Estas evidencias, datadas entre los Flavios y principios de la tercera centuria y documentadas dentro o fuera del territorio tarraconense, revelan su procedencia cívica (origo) de la colonia, su patria local, que en algún caso pudo no coincidir con su lugar de nacimiento, como expondremos más adelante. La expresión domo Tar(r)acone, en relación con un liberto documentado en Narbo (Narbona), precisa su residencia o domicilio en la colonia, sin que se pueda establecer una correspondencia directa con su patria local ${ }^{25}$ (cf. infra tablas I.1-2).

Entre estos Tarraconenses singularizados destacan los homenajes estatuarios erigidos por el concilium provinciae o por privados a quienes fueron magistrados competentes en la colonia y/o flámines en el concilium (CIL II ${ }^{2} / 14.2,1113,1155$; CIL II $\left.2 / 14.3,1216\right)$, documentando en algunos casos un cursus ecuestre (CIL $\left.\mathrm{II}^{2} / 14.2,1132,1156\right)$ o senatorial (CIL $\left.\mathrm{II}^{2} / 14.2,981\right)$. Las evidencias procedentes del ager Tarraconensis son, asimismo, ilustrativas del destacado poder económico que detentaron algunos de los miembros de las familias en las que se integraron estos magistrados con mención de la origo Tarraconensis, en particular cuando en el documento epigráfico - localizado fuera de Tarraco- no se indicó el cursus honorum del notable. Fue el caso de L. Minicius Apronianus (IRC 1,34), aedilis, quaestor, IIvir

25. Sobre la mención de la origo y la domus en la documentación epigráfica, $c f$. J. M. Lassère, Manuel d'épigraphie romaine. 1: L'individu - la cité, París 2007, 128-132; P. Le Roux, "Identités civiques, identités provinciales dans l' Empire romain”, en A. Caballos, S. Lefebvre (Eds.), Roma generadora de identidades. La experiencia hispana, Madrid 2011, 7-19, cit. 8-11. 
et quinquennalis y flamen Divi Traiani Parthici, propietario de una villa localizada en el actual municipio de Perafort, dentro de la provincia de Tarragona (IRAT 8) ${ }^{26}$.

Por otra parte, no hay que olvidar que Tarraco fue un foco de atracción político-administrativo y económico relevante entre quienes no formaron parte de sus habitantes de pleno derecho. Su condición de sede de la administración de la considerada más extensa provincia del Imperio romano se observa en la concentración de evidencias epigráficas relativas a la aristocracia imperial y a las milicias ecuestres; a la élite provincial; a la presencia de militares, en activo o veteranos; además de todas las funciones burocráticas inherentes al officium del gobierno provincial ${ }^{27}$. La documentación procedente del ager Tarraconensis también aporta testimonios correspondientes a esta gestión provincial. Destacan las referencias relativas a tres senadores de rango pretorio de la primera centuria, bien en posesión de villae (IRAT 4, 7) o bien con algún vínculo con quien era su propietario (IRAT 5), así como el recuerdo en la segunda centuria de quien había desempeñado el flaminado provincial (IRAT 93) o tenía vinculos familiares con flamines provinciae (IRAT 27).

Entre estos ámbitos de representación social variable en Tarraco, si se considera la residencia temporal - salvo excepciones - en función de las actividades político-administrativas desempeñadas, se advierte una procedencia itálica y provincial externa en gran parte, pero también hispana. Dentro de este último grupo son en particular ilustrativas las evidencias relativas a «Hispani/-ae Tarraconenses» que de forma transitoria fueron miembros del concilium provinciae o asumieron determinadas funciones en interés de su provincia. Disponemos de significativos registros de su procedencia cívica y/o conventual, destacando los homenajes erigidos o autorizados por el propio concilio entre los principados de los Flavios y Antoninos básicamente, con alguna evidencia en época de Septimio Severo ${ }^{28}$. Permiten observar, desde el corpus epigráfico que atesora la capital provincial, con evidencias valiosas sobre diferentes civitates que integran su demarcación administrativa, los cambios institucionales y los procesos de integración jurídica y política que estaban experimentando en época imperial las comunidades de origen de selectas élites de rango decurional y, en algunos casos, ecuestre,

26. Sobre estos y otros magistrados y decurio representados en el ager Tarraconensis, propietarios de villae, cf. IRAT 9 (L. Aemilius Sempronius Clemens Silvanianus), IRAT 10 (L. Aelius Polycletus) e IRAT 41-42 y 51-53; E. Melchor, "Entre la urbs y el fundus: conmemoración funeraria y honorífica de las élites locales hispano-romanas en sus propiedades rústicas", Veleia, 30, 2013, 119-142, cit. 123,128.

27. Haensch, op. cit., 1997; G. Alföldy, "Fasti und Verwaltung der hispanischen Provinzen: zum heutigen Stand der Forschung", en R. Haensch, J. Heinrichs (Eds.), Herrschen und Verwalten. Der Alltag der römischen Administration in der Hohen Kaiserzeit. Kolloquium zu Ehren von Werner Eck (Köln, 28.-30.1.2005), Köln 2007, 325-356; P. Ozcáriz, La administración de la provincia de Hispania citerior durante el alto Imperio romano: organización territorial, cargos administrativos y fiscalidad, Barcelona 2013, 97-254.

28. En Tarraco se concentra el mayor número de evidencias disponibles, relativas a provinciales que integraron el concilium provinciae entre las dinastías Flavia y Antonina, con homenajes erigidos o autorizados por el propio concilio, frente a los otros dos concilia provinciales, reunidos en Emerita Augusta y en Corduba, cf. Fishwick, op. cit., 2002, 73-85, 139-141, 215-223; E. Ortiz de Urbina, "La exaltación de la élite provincial. Los homenajes estatuarios decretados o autorizados por la provincia Hispania citerior", Epigraphica, 68, 2006, 45-84, cit. 46-50. 
así como de algunos principales de la legio VII Gemina, que en su condición de beneficarii consulares estuvieron al servicio del gobernador provincial con rango consular ${ }^{29}$ (cf. infra tablas II.1-3).

Nos ocupamos a continuación de esta memoria epigráfica significativa, comenzando por los habitantes de pleno derecho de Tarraco. Su vinculación cívica con la colonia y sede provincial tuvo que ser evidente dentro de los límites del territorio asociado desde instancias romanas. No obstante esta alusión a la patria local se precisó en determinados contextos oficiales, en los que se debía documentar la origo, o privados, en los que interesaba destacar su relevante procedencia, sin dejar lugar a dudas de su condición de cives de la colonia y ciudadanos romanos, evitando una posible confusión con los residentes domiciliados (incolae).

\section{II.1. Tarraconenses}

La referencia cívica u origo Tarraconensis se documenta dentro de la colonia en siete dedicaciones honoríficas, con carácter público y privado. Parecen estar motivadas por el deseo de dejar constancia del protagonismo (cívico, provincial o dentro de la aristocracia imperial) de diversos Tarraconenses que son recordados con sus tria nomina y en cinco casos con la mención de su adscripción a una tribus romana (Galeria, Palatina, Quirina), aludiendo a su condición de cives Romani o a su patria communis. Entre estos cives destacan los tres homenajes estatuarios erigidos por la provincia Hispania citerior a flamines provinciae (CIL $\mathrm{II}^{2} / 14.2,1113,1155$ y 1156 ) que habían formado parte de su concilio, en cuyos pedestales se indicó su procedencia cívica, una referencia que debía tener un carácter oficial en estas conmemoraciones públicas ${ }^{30}$. Dos de estos flamines, homenajeados en época de Adriano o poco después, fueron hermanos, miembros de la selecta gens de los Numisii y magistrados locales competentes de la colonia, si tenemos en cuenta la referencia al desempeño de omnes honores en su res publica. Su competencia se proyectó fuera de Tarraco, obteniendo ambos una promoción al ordo equester con anterioridad a sus atribuciones dentro del concilio provincial ${ }^{31}$.

Las cuatro dedicaciones privadas donde la indicación de la origo era una referencia espontánea, remiten a dedicantes del ámbito familiar que ponen de relieve los destacados cursus honorum de sus parientes o, en un caso, de su patronus. Entre estos cursus honorum sobresale el de L. Fulvius Numisianus, vir clarissimus, que es admitido en el ordo senatorius

29. J. J. Palao, Legio VII Gemina (Pia) Felix. Estudio de una legión romana, Salamanca 2006, 135-136.

30. Si se tiene en cuenta las estipulaciones conocidas a través de la Lex de flamonio provinciae Narbonensis, cf. C. H. Williamson, "A Roman Law from Narbonne”, Athenaeum, 65, 1987, 173-189, cit. 178, 11. 11-13: [Si placuerit ius sta]tuae ponendae nomenque suum patrisque et unde sit et quo anno fla[men fuerit inscribendi permitti, ei Narbo]ni intra fines eius templi statuae ponendae ius esto.

31. CIL II ${ }^{2} / 14.2,1155,1156$ y CIL $\mathrm{II}^{2} / 14.3,1213$. En este último epígrafe, una dedicación privada erigida para Montanus por su hermana Numisia Victorina se precisa su condición de aedilis, quaestor y IIvir en dos ocasiones, asumiendo en la segunda competencias censuales (quinquennalis) en Tarraco, iudex en la primera decuria del album iudicum para los tribunales públicos con sede en Roma y su promoción al ordo equester por el emperador Adriano, cf. Ortiz de Urbina, loc.cit., 2006, 67-68.

Revista de Historiografía 25, 2016, pp. 317-341 
mediante una adlectio inter tribunicios desarrollada por el emperador Cómodo (CIL II²/14.2, 981). Su adscripción a la tribus Quirina, y no a la Galeria en la que se evidencia que fueron censados la mayoría de los ciudadanos de la colonia, así como la documentación de $L$. Fulvii en Aeso (Isona), ha permitido considerar que este senador podría haber tenido una ascendencia familiar o un origen foráneo, habiendo recibido la ciudadanía tarraconense con posterioridad. En este sentido, se podría entender el interés de su hermana -homónima de una clarissima femina documentada en Tarraco y probable descendiente del senador (CIL $\left.\mathrm{II}^{2} / 14.2,980\right)$ - en destacar en el pedestal que le erigió, posiblemente en el foro de la colonia, no solo su prestigioso cursus honorum, sino también su condición de Tarrac(onensis) y el nomen y cognomen paterno en su filiación ${ }^{32}$. Por otra parte, no es el único senador documentado en Tarraco que es admitido en el ordo mediante adlectio, pero en ninguno de los dos pedestales privados en los que se ha transmitido la fórmula onomástica (CIL II ${ }^{2} / 14.2,975$ y 990) se precisa la origo, siendo uno de los adlecti oriundo probablemente de Cirta (Numidia).

Asimismo, otros dos homenajes estatuarios erigidos a expensas privadas, posiblemente post mortem, ponen de relieve las atribuciones asumidas por dos Tarraconenses dentro de su res publica (CIL II $\mathrm{I}^{2} / 14.2,1132$ y $\left.C I L \mathrm{II}^{2} / 14.3,1216\right)$. La precisión de la origo se desarrolla en ambos casos por iniciativa de los dedicantes: la liberta de C. Egnatuleius Seneca con posterioridad al principado de Tito y los herederos de M. Valerius Vindex en el siglo segundo o principios del tercero. Esta precisión permite pensar en un interés particular de los dedicantes en que fuera recordada su adscripción cívica, máxime si no pertenecían a las familias más célebres de la colonia, aunque Egnatuleius hubiera sido promocionado al ordo equester y nombrado flamen provinciae ${ }^{33}$.

Por otra parte, también especifica la origo Tarraconens(is), apenas abreviada (CIL $\mathrm{II}^{2} / 14.2,1027$ ), un sevir mag(ister) Larum Aug(ustalis) (CIL II $\left.{ }^{2} / 14.3,1251\right)$ : M. Fabius Asiaticus. Erige un homenaje estatuario al probable hijo de su patrono ${ }^{34}$, M. Fabius Paulinus, indicando su promoción al ordo equester por el emperador Adriano y recordándolo como amantissimus paternarum amicitiarum. En esta referencia cívica habría que considerar el interés de Asiaticus en identificar su adscripción jurídica a la colonia, siendo Paulinus civis optimus de Ilerda (Lérida) (CIL II²/14.2, 1026).

Fuera de Tarraco se documentan tres menciones que precisan una procedencia de la colonia $^{35}$. En dos casos, disponemos de la referencia a la origo, con un ejemplo en la provincia Citerior, en un núcleo adscrito al conventus Tarraconensis $(\operatorname{IRC} 1,34)$ y uno en la capital

32. J. López, "Contribución a la prosopografía senatorial hispánica: L. Fuluius Numisianus, adlectus tarraconense", AespA, 72, 1999, 281-286. En relación con las tribus documentadas en Tarraco, cf. D. Fasolini, Le tribù romane della Hispania Tarraconensis: l'ascrizione tribale dei cittadini romani nelle testimonianze epigrafiche, Milano 2012, 442-454.

33. G. Alföldy, "Drei städtische Eliten im römischen Hispanien”, Gerion, 2, 1984, 193-238, cit. 201-202.

34. Como se propone en CIL II ${ }^{2} / 14.2,1027$, frente a la interpretación de que sea su padre, $c f$. J. Andreu, "Sentimiento y orgullo cívico en Hispania: en torno a las menciones de origo en la Hispania citerior", Gerión, 26.1, 2008, 349-378, cit. 361-362.

35. Se descarta la dedicación votiva hallada en Sagunto, teniendo en cuenta la lectura y comentario del epígrafe en CIL $\mathrm{II}^{2} / 14.1,726 \mathrm{a}$. 
de la provincia Lusitania $(A E$ 1915, 34). No tenemos información sobre los motivos de estas menciones fuera de Tarraco. En el testimonio localizado en Aquae Calidae (Caldes de Montbui) en honor de Apolo se refiere a un miembro de una de sus familias destacadas, los Minicii, un nomen con amplia representación en el conventus Tarraconensis ${ }^{36}$. El de Emerita Augusta (Mérida) alude a un músico (cornice[n]), que pudo formar parte de una asociación de cornicines de y al servicio de la colonia ${ }^{37}$. Esta práctica ausencia de referencias precisas fuera de Tarraco parece remitir a la permanencia de sus cives en una colonia que destacaba en el ámbito hispano y del Occidente romano por su relevante proyección socio-económica y político-administrativa. La tercera mención relativa a una procedencia de Tarraco se registra en una inscripción funeraria hallada en Narbo (Galia Narbonense) (CIL II $2 / 14.2$, E 3). En este caso, la expresión domo Tar(r)acone, en ablativo, referida a un liberto de la gens Afrania (CIL $\mathrm{II}^{2} / 14.2,833$ ), precisa su residencia o domicilio en la colonia, sin que se pueda establecer una correspondencia directa con su patria local u origo, como hemos señalado. No obstante, no sería descartable suponer que Tarraco pudiera haber sido también la tierra natal o el lugar de nacimiento del liberto L. Afranius Eros ${ }^{38}$.

\section{II.2. «Hispani/-ae Tarraconenses»}

Un corpus de sesenta y seis hispanos/-as procedentes de Hispania citerior se documenta en Tarraco entre la dinastía Flavia y el siglo III, con la referencia en las dedicaciones de las que fueron objeto o en las que actuaron como dedicantes (con carácter honorario en su mayoría y funerario en algunos casos, además de un sello de bronce) de su procedencia cívica (origo) y/o conventual (ex conventu) de diferentes áreas de la provincia o su residencia o domicilio (domus) en dos núcleos de este ámbito administrativo (cf. infra tablas II.1-4). Su designación como "Hispani/-ae Tarraconenses», en alusión a la identificación administrativa provincial, nos parece oportuna si se considera la mención de la procedencia - mediante la expresión natio (en ablativo) $)^{39}$ - en un epitafio, hallado en Carnuntum, Panonia superior (CIL $\mathrm{II}^{2} / 14.2$, E 4) y datado aproximadamente a finales del siglo II: nation(e) Hispan(us) Tarraconensis. El

36. J. Andreu, P. Otiña, Ò. Curulla, "Los Minicii de Tarraco en torno a un nuevo documento epigráfico tarraconense", Epigraphica, 70, 2008, 103-117, cit. 108-109. L. Minicius Apronianus asumió destacadas responsabilidades en la gestión local de Tarraco, como evidencia su función como IIvir q(uin)q(uennalis) (CIL II²/14.2, 819).

37. Sobre los diferentes tipos de asociaciones profesionales de músicos documentadas en Italia y las evidencias de su presencia en Hispania y en otras provincias el Occidente romano, sin referencia a estructuras asociativas, $c f$. A. Vincent, "Les collèges de musiciens. Pratiques professionnelles et insertion civique”, en M. Dondin-Payre, N. Tran (Eds.), Collegia. Le phénomène associatif dans l'Occident romain, Bordeaux 2012, 183-198, cit. 197-198.

38. Sobre la expresión domus en la documentación epigráfica, cf. supra n. 25.

39. Sobre la expresión natio en la documentación epigráfica, $c f$. Lassère, op. cit., 2007, 132-134. 
difunto es un veteranus ex magistr(o) navaliorum de la legio XIIII Gemina ${ }^{40}$, que indica su nacimiento en una de las provincias hispanas, designada como Hispania Tarraconensis, también documentada con esta expresión - frente a la habitual Hispania citerior - en otras inscripciones $\left(C I L \mathrm{II}^{2} / 14.1,20\right)^{41}$. La expresión nat(ione) Tarracone, sin embargo, documentada en Roma (CIL II ${ }^{2} / 14.2$, E 1), y datada con posterioridad al siglo II, se precisa en un epitafio dedicado a su hijo por dos servi para indicar su lugar de nacimiento, sin que Tarraco pueda considerarse su patria naturae ${ }^{42}$, si se tiene en cuenta la condición servil de los ancestros ( $c f$. infra tabla II.5).

Entre los cincuenta y cuatro «Hispani Tarraconenses» del corpus objeto de estudio se registran influyentes notables de la provincia, si exceptuamos las doce «Hispanae Tarraconenses» mencionadas, excluidas de toda participación político-administrativa directa. Únicamente, entre estas doce féminas se documenta en algunos casos el ejercicio del flaminado en la capital provincial, desplazándose de diferentes áreas de la Citerior: CIL II²/14.2, 1177: ex cconventuد Cluniens(i); 1180: Amocensis Cluniens(is) ex gente Cantabro(rum); 1181: ex

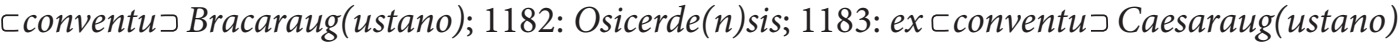
Karensis; 1184: Pompaelonensis; 1185: Segobrig(ensis) ex ᄃconventu Carthag(iniensi).

Entre los notables reputados destacan los que han recibido un homenaje estatuario del concilium provinciae. Estos homenajes oficiales conmemoran que habían desempeñado el flaminado provincial, normalmente después de haber sido magistrados competentes en sus comunidades de procedencia - con el desempeño en varios casos de un completo cursus honorum, precisado mediante la fórmula abreviada omnes honores in re publica sua functo-, o suponen el reconocimiento de determinadas atribuciones desarrolladas en interés de la provincia (legationes, cura tubulari(i) censualis). Las referencias a estas treinta y ocho dedicaciones honoríficas se indican en las tablas finales (II.1-3) y han sido estudiadas en una contribución anterior ${ }^{43}$. También fueron conmemorados por el concilio miembros del orden ecuestre que acreditaron el desarrollo del flaminado provincial: CIL $\mathrm{II}^{2} / 14.2,1111$ : ex conven[tu] Carthag(iniensi) Attace[nsis]; 1121: Alabensis ex cconventu Carthag(iniensi); 1125: ex conven [t(u)] Cesar(augustano) Ercavic(ensis); 1133: Saet[abitanus]; pos. 1162: Cantabr(us) Iuliobrig(ensis); 1166: Calagorrit(anus); 1171: Edetanus; 1173: Libisosanus; González, Ortiz de Urbina 2015: Adovus ex ᄃconventu Lucen[sium].

40. E. Weber, "Ein magister navaliorum in Carnuntum”, en W. Eck, B. Fehér, P. Kovács (Eds.), Studia epigraphica in memoriam Géza Alföldy, Bonn 2013, 377-381. Weber considera su condición hispana, con procedencia de Tarraco (378).

41. Cf. las menciones prov(incia) Hisp(ania) Tarraconen(sis), provincia Tar[racone]nsis, prov(incia) Hispa[nia cite] rioris Tarrac(onensis) en Haensch, op. cit., 1997, 486-488; P. Le Roux, "Géographie péninsulaire et épigraphie romaine” en Cruz, Le Roux, Moret (Eds.), loc. cit., 2007, 197-219, cit., 209.

42. C. Ricci, "Hispani a Roma", Gerión, 10, 1992, 103-143, cit., 117-120. La autora propone una datación de fines del siglo I e inicios del siglo II y considera que la madre de Corbulo, nat(ione) Tarracone, era liberta (120).

43. Un análisis detallado de estas evidencias lo hemos realizado en Ortiz de Urbina, loc. cit., 2006, 46-67, 79-83. 
Al margen de estos homenajes de la provincia con indicación de la pertenencia a estos dos ordines, decurional y ecuestre, se sitúa la dedicación honoraria de su res publica a un flamen designatus provinciae, que posiblemente aún no había iniciado el desarrollo de sus atribuciones [CIL II $2 / 14.2$, 1117: Flaviaugustanus]. Por otra parte, entre las dedicaciones funerarias se constatan, asimismo, quienes habían desarrollado funciones en la legio VII Gemina como principales, siendo beneficiarii consulares al servicio del gobernador provincial [CIL II ${ }^{2} / 14.2$, 1045: civis Asturic(ensis); 1056: Toletanus] o un veterano, antiguo beneficarius vinculado al officium de un alto cargo en Tarraco [IRAT 13: civ(is) Bracar(augustanus)]; o como milites legionis [CIL II ${ }^{2} / 14.2,1067$ : d(omo) Selglisama Brasaca; 1070: Brac(arus)]. Entre los no ingenui se encuentra la mención de un magister Larum que actúa como dedicante del titulus a la memoria de su esposa liberta [CIL II²/14.3, 1266: Uxamens(is)].

Algunos de los provinciales homenajeados o fallecidos en la capital provincial dispusieron de propiedades en el ager Tarraconensis, documentando un relevante poder económico. Entre otros, destaca C. Valerius Avitus, propietario de la villa de 'Els Munts' (Altafulla) (IRAT 34, 35) ${ }^{44}$, originario de Augustobriga (Muro de Ágreda, Soria), translatus ab Divo Pio ex municipio August(obrigensi) in col(oniam) Tarrac(onensium), llegó a ser IIvir en la colonia (CIL II $\left.{ }^{2} / 14.3,1215\right)$. Se ha considerado la posibilidad de que Sulpicius Sabinus, oriundo de Bracara Augusta (Braga), hubiera recibido tierras en Tarraco por su condición de veterano (IRAT 13). En otros casos, son los dedicantes quienes precisan un origen provincial y su relación con destacados miembros de la élite tarraconense, como demuestra el pedestal que C. Apu[l]eius Lup[us], originario de Complutum (Alcalá de Henares) le dedica a un magistrado de la colonia de Tarraco, al que califica de amicus, siendo un probable cliente suyo. Esta dedicación honorífica, como se ha propuesto (IRAT 9) ${ }^{45}$, pudo decorar la villa propiedad del homenajeado.

Por otra parte, además de esta representación y memoria epigráfica de quienes fueron homenajeados, de forma pública o privada, o de aquellos que fallecieron en la capital provincial, este corpus conservado en Tarraco constituye un archivo de información significativo, que revela la diversidad histórico-cultural y regional que caracteriza a la extensa Hispania citerior, que no se observa en otras provincias hispanas ${ }^{46}$. Nos permite examinar con detalle, dentro de la dinámica de cambios estimulada por el Estado romano, los procesos de inte-

44. Melchor, loc. cit., 123; J. Ruiz de Arbulo, "El signaculum de Caius Valerius Avitus, duoviro de Tarraco y propietario de la villa de Els Munts (Altafulla)”, Pyrenae, 45.1, 2014, 125-151, cit. 126-132, 138.

45. En el ager Tarraconensis también se encuentran evidencias de posibles selectas féminas. En este sentido, se ha sugerido que el emplazamiento originario del pedestal honorífico post mortem de Sulpicia, oriunda de Calagurris (Calahorra), matr[o]na honest [is] sima, uxo[r] pudic[is]sima, mater p[ii]ssimae, erigido por su esposo e hija, debió de ser una villa de la zona de Constantí, quizás Centcelles, aunque sin datos precisos por el momento (IRAT 33). Sobre esta representación familiar, $c f$. E. Ortiz de Urbina, "La proyección de la élite de los vascones en época romana. Representación local, provincial y estatal”, en J. Andreu (ed.), Los Vascones de las fuentes antiguas: en torno a una etnia de la Antigüedad peninsular, Barcelona 2009, 457-478, cit. 471, n. 74.

46. Cf. A. Caballos, "La Bética como referente identificador en la documentación epigráfica”, en Caballos, Lefebvre (Eds.), loc. cit., 185-207, cit. 189-191. 
gración política que estaban experimentado en época imperial las civitates adscritas a esta provincia, por la variedad y dispersión en el ámbito provincial de las procedencias citadas, datadas en un amplio periodo cronológico — entre la dinastía Flavia y el siglo III - y relativas a quienes fueron objeto de la dedicación o, en algunos casos, a quienes actuaron como dedicantes. En concreto, los sesenta y seis provinciales registrados transmiten cincuenta y ocho referencias de su procedencia cívica (origo) — nueve de ellas con la mención también del conventus-; seis menciones en las que se precisa únicamente la procedencia del conventus; y dos alusiones relativas a la residencia o domicilio (domus).

Las civitates documentadas como referencia de origo son cuarenta y ocho en total y para diez de ellas disponemos de más de un testimonio ( $c f$. infra tablas II.1-2). En la secuencia onomástica se incluye un adjetivo relativo a la adscripción cívica y, de forma excepcional, el nombre de la comunidad en ablativo ${ }^{47}$. Otras expresiones de diferente carácter identificador, como veremos a continuación, fueron añadidas a este adjetivo de reconocimiento cívico en varios testimonios. Funcionó, asimismo, como adjetivo calificativo de civis [CIL $\mathrm{II}^{2} / 14.2$, 1045: civis Asturic(ensis); IRAT 13: civ(is) Bracar(augustanus)] en dos dedicaciones funerarias, las más tardías del corpus, datadas en el siglo III. De esta forma, quedaba señalada la ciudadanía concerniente a la patria naturae o loci de estos cives, integrados asimismo en la patria civitatis o iuris por su condición de cives Romani, empleando las expresiones ciceronianas relativas a las dos patriae (De legibus 2.2.5).

En una de las evidencias se constata una doble origo, precedida en la secuencia onomástica de una referencia relativa al área geográfica (Plin. NH. 3.76-77) o marítima (Plin. NH. 3.74) en la que se localizaban ambas comunidades cívicas ${ }^{48}$ : Balearicus Palmensis et Guiuntanus (CIL II²/14.2, 1140). En ambas res publicae Cn. Gavius Amethystus desempeñó omnibus honoribus con anterioridad a su probable flaminado provincial. Una de ellas sería la comunidad cívica a la que fue adscrito jurídicamente desde su nacimiento a través de su filiación paterna, probablemente Guium por su incorporación a la Quir(ina) tribus, siendo la Velina tribus la relativa a los cives de Palma. Con posterioridad recibiría la receptio in civium numerum en Palma o la adlectio in ordinem, como el Gralliensis y el Damanitanus adlecti in ordine/coloniam Caesaraugustanam (CIL II $2 / 14.2,1165$ y 1169$)^{49}$.

Otras referencias, que fueron grabadas con anterioridad o posterioridad a la mención de origo, aportaban elementos de identificación diversos al cívico o al geográfico mencionados. Destacan entre estas indicaciones la adscripción al conventus en cinco de los siete que Plinio refiere cuando describe la provincia (NH 3. 23-28). La aclaración ex conventu

47. Cf. Augustobriga (IRAT 34) en un sello de bronce. En CIL II²/14.2, 1159 no sería descartable la lectura Brac(arus) Aug(ustanus), documentada en otras referencias de origo (CIL II ${ }^{2} / 14.2,1070$ y IRAT 13). Asimismo, la lectura Casc(antinus) se documenta en $A E$ 2006, 606: [C]ascantinus y la hemos precisado en las tablas finales (II.1.), frente a $\operatorname{Casc}($ anto).

48. Cf. Baliares insulae y Baliaricum mare en Tabula Imperii Romani. Hoja K/J-31 (Tarraco, Baliares), 42-43, 85 .

49. Cf. supra n. 25; Sobre las tribus de adscripción de Guium y Palma y la permanencia de la tribus de origen o la adquisición de otra tribus cf. Fasolini, op. cit., 8-9, 12-13, 304-305, 381-383. Se debe corregir en esta última página Quirina, en vez de Galeria, cuando el autor se refiere a la tribus de Cn. Gavius Amethystus. 
(Bracaraugustanus, Lucensium, Caesaraugustanus y Carthaginiensis) o mediante un adjetivo (Cluniensis) en nueve evidencias del corpus (cf. infra tabla II.2) pone de relieve la función identificadora de estas circunscripciones intraprovinciales en la extensa Hispania citerior. Permitiría localizar con mayor exactitud o resaltar el entorno intraprovincial de la comunidad cívica en la que se integraban quienes dejaron memoria epigráfica de la misma, máxime si eran los primeros en disponer de un homenaje en Tarraco, decretado o aprobado por el concilio provincial, o sus procedencias cívicas carecían de renombre entre los provinciales y en la capital provincial ${ }^{50}$.

La especificación de la circunscripción conventual desempeñó, en particular, una función identificadora oportuna en cuatro conventus - los tres del Noroeste y el Cluniensis-, donde desde época augústea habían sido adscritos los últimos territorios conquistados por el poder romano. Plinio no empleó para la enumeración de las comunidades que los integraban (NH. 3.26-28) un criterio jurídico romano, que tuviera en cuenta, a partir de la formula provinciae de época augústea, los populi civium Romanorum, populi Latinorum, populi foederatorum, populi stipendiariorum. Este criterio sí lo utilizó (NH. 3.23-25) en los tres que completan la descripción de la provincia (Caesaraugustanus, Carthaginiensis, Tarraconensis), con reconocidos populi que disfrutaban de la civitas Romana y del ius Latii ${ }^{51}$. A partir de la información aportada por el naturalista se puede profundizar en las referencias epigráficas relativas a estos cuatro conventus del corpus analizado, datadas a partir de los Flavios, salvo alguna excepción (CIL II²/14.3, 1298).

Respecto a las tres menciones epigráficas del conventus Cluniensis (cf. infra tabla II.23), dos fueron precedidas por la indicación de la procedencia cívica (Amocensis, Intercatiensis), pero también se señaló su gens o grupo de población (Cantabri, Vaccaei) (CIL II ${ }^{2} / 14.2$ $1180,1114)$, como en el caso de dos Iuliobrigenses (CIL II ${ }^{2} / 14.21162,1191$ ), para los que se destacó su pertenencia a los Cantabri. En estas cuatro dedicaciones del concilio provincial a «Hispani/-a Tarraconenses» desplazados/-a a Tarraco, la origo o referencia cívica constituía la alusión esencial para su identificación desde una perspectiva administrativa romana. La mención del conventus aportaba un elemento de identificación potestativo en estos homenajes, relativo a su inserción en la estructuración de la provincia hispana más extensa y diversificada desde una perspectiva histórico-cultural. La indicación de la gens o grupo de población, siendo opcional y de naturaleza étnica, añadiría un elemento de reconocimiento dentro de este conventus, con un desarrollo urbano no comparable al de los tres conventus del área más oriental de la provincia. Ya en época augústea el naturalista adjudicaba al conventus Clunien-

50. Cf. supra n. 43.

51. Cf. un estudio pormenorizado de la descripción del espacio provincial en Plinio en P. Ciprés, "Hispania citerior en la geografía de Plinio",Veleia, 31, 2014, 15-32; asimismo en esta publicación su contribución relativa a "Los datos geográficos en la descripción de Hispania en la Naturalis Historia de Plinio". Sobre la ciudadanía romana y el derecho latino y los debates historiográficos recientes, $c f$. E. Ortiz de Urbina, "Derecho latino, organización cívica y élites hispanas", en J. Santos, G. Cruz Andreotti (Eds.), Revisiones de Historia Antigua VII: Romanización, fronteras y etnias en la Roma antigua: el caso hispano, Vitoria-Gasteiz 2012, 631-664. 
sis la mayor concentración de comunidades cívicas (populi) y políticas (civitates) - sesenta y nueve en total, con pocos núcleos urbanos o ciudades (oppida) - en toda la estructuración conventual de la provincia, indicando los pueblos o gentes para ordenar las diferentes menciones cívicas y políticas relativas a la administración romana ${ }^{52}$. Estas se estructuraban en seis oppida; treinta y un populi, estipendiarios probablemente - salvo excepciones como Flaviobrica colonia (NH. 4.110) -, localizando entre los nueve del grupo de población de los Cantabri únicamente (sola memoretur) a Iuliobriga; así como treinta y dos civitates, entre ellas diecisiete de los Vaccaei, destacando Intercatia entre las que fueron famosas (NH. 3.26-27).

Por otra parte, la referencia ex conventu, sin la origo o procedencia cívica, es la única mención indicada para identificar dentro de la provincia a seis "Hispani/-ae Tarraconenses» procedentes de los conventus Bracaraugustanus (cuatro epígrafes), Lucensium y Cluniensis (con una mención respectivamente cada uno) (cf. infra tabla II.3). Únicamente dos de estos seis epígrafes tienen un carácter privado, siendo tres erigidos por el concilio provincial ( $C I L$ $\left.\mathrm{II}^{2} / 14.2,1168,1174,1181\right)$ y uno por los cives $\left[\right.$ Ta]rrac(onenses) $\left(C I L \mathrm{II}^{2} / 14.2,1177\right)$.

En los cuatro homenajes públicos, en apariencia insólitos desde una perspectiva administrativa romana por la ausencia de la origo, habría que considerar que tanto el concilio provincial como los ciudadanos tarraconenses debieron de optar por el elemento de identificación más adecuado desde una perspectiva romana para el reconocimiento oficial de estos cuatro provinciales. Su adscripción a tres conventus con un desarrollo urbano limitado, en comparación con los tres del área oriental de la provincia, permite pensar que procederían de comunidades cívicas todavía en la segunda mitad del siglo II poco importantes y de nombre bárbaro (populi ignobilium ac barbarae apellationis) o de comunidades políticas (civitates) que, en su caso, no se podrían nombrar sin fastidium, teniendo en cuenta los comentarios del naturalista, tanto el expuesto para el conventus Cluniensis como los relativos a los dieciseis populi y veinticuatro civitates de los dos conventus del extremo occidental de la provincia ( $\mathrm{NH}$. 3.28). Es posible suponer que su origo no coincidiría con algunas de las referencias cívicas relativas a los tres conventus que fueron dignas de mención epigráfica en Tarraco: Amoca, Aquae Flaviae, Augustobriga, Avobriga, Bracara Augusta, Intercatia, Iuliobriga, Palantia, Segontia, Uxama, Viminacium y quizás Flaviaugusta, así como las civitates de los Limici y de los Adovi (cf. infra tabla II.1-2).

La referencia ex conventu Asturum — con o si la indicación de origo- no se documenta en el corpus analizado. No obstante, esta mención añadida a la origo de un Brigiaecinus (CIL $\left.\mathrm{II}^{2} / 14.2,1135\right)$ y de un Lancien[s(is)] (CIL II $\left./ 14.2,1146\right)$ - los únicos notables conocidos de esta circunscripción conventual con homenajes públicos en Tarraco-sería innecesaria por implícita ${ }^{53}$ : en sus pedestales estatuarios se recordaba que habían ejercido como sacerdotes Romae et Augusti conventus Asturum.

52. Sobre esta función de identificación de las gentes en la descripción del conventus Cluniensis, cf. Ciprés, loc. cit., 2014.

53. Cf. también el ejemplo del Limicus sacerdos convent(us) Bracari (CIL II ${ }^{2} / 14.2$, 1136). En otras menciones del sacerdocio conventual —en particular CIL II²/14.2, 1114 y 1145 -, constatado únicamente en los homenajes del concilio a flámines provinciales del conventus Cluniensis y en los tres del Noroeste, no 
A modo de conclusión, al término de este análisis relativo a la memoria epigráfica cívica y provincial, transmitida en los setenta y ocho epígrafes analizados - setenta y tres procedentes de Tarraco-, se observa que Tarraconenses e «Hispani/-ae Tarraconenses» confluyeron en esta "ciudad del poder», que destacó en el ámbito hispano y en el Occidente romano por su relevante proyección. Esta confluencia entre habitantes de pleno derecho (nacidos o no en Tarraco) y provinciales con residencia temporal o permanente en la colonia y capital provincial, procedentes de diferentes ámbitos cívicos de la Citerior, fue extendiéndose progresivamente, en conexión con los procesos de (re)organización política que desde instancias romanas se estaban desarrollando en la más diversificada - desde una perspectiva históricocultural- de las provinciae hispanas.

se repite la mención del conventus en el mismo pedestal estatuario, como hemos reflejado recientemente: Ma C. González, E. Ortiz de Urbina, "Élites locales de Hispania citerior a las puertas de la élite imperial: observaciones a propósito del CIL II²/14.2, 1145 y 1188”, en A. Caballos, E. Melchor (Eds.), De Roma a las provincias: las élites como instrumento de proyección de Roma. Juan Francisco Rodríguez Neila in honorem, Sevilla 2015, 519-541, cit. 529-534. 


\section{CORPVS EPIGRÁFICO}

\section{1. Tarraconenses en Tarraco: mención de la origo}

\begin{tabular}{|c|c|c|c|c|c|}
\hline ORIGO & TRIA NOMINA & $\begin{array}{r}\text { CVRSVS } \\
\text { TARRACONE }\end{array}$ & $\begin{array}{l}\text { HONORVM } \\
\text { EXTRA TARRACONEM }\end{array}$ & TITVLVS & REFERENCIA \\
\hline $\operatorname{Tar}[\operatorname{rac}($ onensis) $]$ & $\begin{array}{l}\text { Cn. Anto[nius] } \\
\text { Avitus }\end{array}$ & flame $[n]$ pro $[v($ inciae $)]$ & & $\begin{array}{l}\text { T. honorarius } \\
\text { (p. H. c.) }\end{array}$ & $\begin{array}{l}C I L \mathrm{II}^{2} / 14.2,1113 \\
(\text { c. } 70-150 / 180)\end{array}$ \\
\hline Tarr(aconensis) & $\begin{array}{l}\text { C. Egnatuleius } \\
\text { Seneca }\end{array}$ & $\begin{array}{l}\text { aed(ilis) } q \text { (uaestor) IIvir } \\
\text { flam(en) Divi Titi } \\
\text { flamen p(rovinciae) }\end{array}$ & $\begin{array}{l}\text { praef(ectus) } \\
\text { coh(ortis) IIII } \\
\text { Thrac(um) } \\
\text { eq(uitatae) }\end{array}$ & $\begin{array}{l}\text { T. honorarius } \\
\text { (liberta) }\end{array}$ & $\begin{array}{l}\text { CIL II }{ }^{2} / 14.2,1132 \\
\text { (f. s. I-p. s. II) }\end{array}$ \\
\hline Tarraconens(is) & $\begin{array}{l}\text { M. Fabius } \\
\text { Asiaticus }\end{array}$ & & & $\begin{array}{l}\text { Fecit } t \text {. honorarium } \\
\text { [amantissimo } \\
\text { paternarum } \\
\text { amicitiarum] } \\
\text { (pos. filio patroni) }\end{array}$ & $\begin{array}{l}\text { CIL II }{ }^{2} / 14.2,1027 \\
\text { (c. } 117-138)\end{array}$ \\
\hline Tarrac(onensis) & $\begin{array}{l}\text { L. Fulvius } \\
\text { Numisianus }\end{array}$ & & $\begin{array}{l}c \text { (larissimus) } v(\text { ir }) \\
\text { tribunicius allectus } \\
\text { in amplissimum } \\
\text { ordinem }\end{array}$ & $\begin{array}{l}\text { T. honorarius } \\
\text { (soror) }\end{array}$ & $\begin{array}{l}C I L \mathrm{II}^{2} / 14.2,981 \\
(\text { c. } 185-191)\end{array}$ \\
\hline Tarrac(onensis) & $\begin{array}{l}\text { L. Numisius } \\
\text { Montanus }\end{array}$ & $\begin{array}{l}\text { omnib(us) honorib(us) } \\
\text { in re p(ublica) sua } \\
\text { functus } \\
\text { flamen p(rovinciae) }\end{array}$ & & $\begin{array}{l}\text { T. honorarius } \\
\text { (p. H. c.) }\end{array}$ & $\begin{array}{l}\text { CIL II }{ }^{2} / 14.2,1155 \\
\text { (Adriano o poco } \\
\text { post.) }\end{array}$ \\
\hline Tarrac(onensis) & $\begin{array}{l}\text { L. Numisius } \\
\text { Ovinianus }\end{array}$ & $\begin{array}{l}\text { omnib(us) honorib(us) } \\
\text { in re p(ublica) sua } \\
\text { funct(us) } \\
\text { flam(en) p(rovinciae) }\end{array}$ & $\begin{array}{l}\text { tribunus } c(o) \\
\text { hort(is) I } \\
\text { Macedonicae }\end{array}$ & $\begin{array}{l}\text { T. honorarius } \\
\text { (p. H. c.) }\end{array}$ & $\begin{array}{l}\text { CIL } \mathrm{II}^{2} / 14.2,1156 \\
\text { (Adriano o poco } \\
\text { post.) }\end{array}$ \\
\hline Tarrac(onensis) & $\begin{array}{l}\text { M. Valerius } \\
\text { Vindex }\end{array}$ & $\begin{array}{l}\text { omnibus honoribus in re } \\
\text { p(ublica) sua functus }\end{array}$ & & $\begin{array}{l}\text { T. honorarius } \\
\text { (heredes) }\end{array}$ & $\begin{array}{l}\text { CIL II } \mathrm{II}^{2} / 14.3,1216 \\
\text { (c. } 120-\text { p. III) }\end{array}$ \\
\hline
\end{tabular}

\section{2. Tarraconenses fuera de Tarraco, con mención de la origo, y domiciliado en Tarraco, con mención de la domus}

\begin{tabular}{|c|c|c|c|c|}
\hline DOMVS & ORIGO & ANTROPONIMIA & TITVLVS & REFERENCIA \\
\hline & [T]arraconensis & L(ucius) Antonius Primus & T. honorarius & $\begin{array}{l}\text { Emerita Augusta } \\
\text { (Mérida) } \\
\text { AE 1915, } 34\end{array}$ \\
\hline & Tarrac(onensis) & L(ucius) Minicius Apronianus & T. honorarius & $\begin{array}{l}\text { Aquae Calidae } \\
\text { (Caldes de Montbui, } \\
\text { Barcelona) } \\
\text { IRC } 1,34 \text { (Adriano) }\end{array}$ \\
\hline $\operatorname{Tar}(r) a c o$ & & $L$ (ucius) Afranius Eros & Fecit t. sepulcralem (filiae) & $\begin{array}{l}\text { Narbo (Narbona) } \\
\text { CIL } \mathrm{II}^{2} / 14.2 \text {, E } 3\end{array}$ \\
\hline
\end{tabular}




\section{II.1. Hispani Tarraconenses en Tarraco: mención de la origo}

\begin{tabular}{|c|c|c|c|}
\hline ORIGO & ANTROPONIMIA & TITVLVS & REFERENCIA \\
\hline Civis Asturic(ensis) & L. Anteius Flavinus & $\begin{array}{l}\text { T. sepulcralis (libertus) } \\
{[\text { b(ene)f(iciarius) } \operatorname{co}(n) s(\text { ularis })]}\end{array}$ & $\begin{array}{l}\text { CIL II } \mathrm{II}^{2} / 14.2,1045 \\
\text { (p. s. III) }\end{array}$ \\
\hline Augustobriga & C. Valerius Avitus & Signaculum & $\begin{array}{l}\text { IRAT } 34 \\
\text { (A. Pío-M. Aurelio) }\end{array}$ \\
\hline Avobrigensis & L. Sulpicius Niger Gibbianus & $\begin{array}{l}\text { T. honorarius (p. H. c.) } \\
{[\text { flam (en) R. D. et A.p(rov.)] }}\end{array}$ & $\begin{array}{l}C I L \mathrm{II}^{2} / 14.2,1167 \\
\text { (c. } 150-180)\end{array}$ \\
\hline [Av]obr[i]gensis & Avitus & $\begin{array}{l}\text { T. honorarius (p. H. c.) } \\
{[[\text { fla]men A[ug. p(rov.)]] }}\end{array}$ & $\begin{array}{l}\text { CIL } \mathrm{II}^{2} / 14.2,1119 \\
\text { (c. } 120-150 / 180)\end{array}$ \\
\hline Ausetanus & C. Marius Nigrinus & $\begin{array}{l}\text { T. honorarius (p. H. c.; ex d.d. Tarrac.) } \\
\text { [flam(en) R. D. et A. provinc.] }\end{array}$ & $\begin{array}{l}\text { CIL II²/14.2, } 1151 \text { y } \\
1152 \text { (1ª m. s. II) }\end{array}$ \\
\hline Barcinonen(sis) & L(ucius) Valer(ius) Latinus & Fecit $t$. honorarium (viro ordinis equestris) & $\begin{array}{l}\text { CIL II } 2 / 14.2,1013 \\
\text { (Flavios - s. II) }\end{array}$ \\
\hline Bergidus F(lavius) & C. Val(erius) Arabicus & $\begin{array}{l}\text { T. honorarius (p. H. c.) } \\
{[\text { ob curam tabulari }(i) \text { censualis ] }}\end{array}$ & $\begin{array}{l}C I L \mathrm{II}^{2} / 14.2,1194 \\
\text { (m. s. II o post.) }\end{array}$ \\
\hline Brac(arus) Aug(ustanus) & Q. Pontius Severus & $\begin{array}{l}\text { T. honorarius (p. H. c.) } \\
{[\text { flam }(\text { en }) p(\text { rov. })]}\end{array}$ & $\begin{array}{l}\text { CIL } \mathrm{II}^{2} / 14.2,1159: \\
\operatorname{Brac}(\operatorname{ara}) \operatorname{Aug}(\text { usta) } \\
\text { (c. 120-150/180) }\end{array}$ \\
\hline $\operatorname{Brac}($ arus) & [-] Rufonius [..]ca $(v) u s$ & $\begin{array}{l}\text { T. sepulcralis } \\
{[\text { mil(es) [leg(ionis)]] }}\end{array}$ & $\begin{array}{l}\text { CIL II }{ }^{2} / 14.2,1070(c . \\
\text { f. s. I) }\end{array}$ \\
\hline Civ(is) Bracar(augustanus) & Sulpic(ius) Sabin(us) & $\begin{array}{l}\text { T. sepulcralis (alumnus et uxor) } \\
\text { [benef(iciarius)] }\end{array}$ & $\begin{array}{l}\text { IRAT } 13 \\
\text { (s. III) }\end{array}$ \\
\hline Brigiaecinus & L. Fabius Silo & $\begin{array}{l}\text { T. honorarius (p. H. c.) } \\
{[\text { flamen } p(\text { rov. })]}\end{array}$ & $\begin{array}{l}\text { CIL II }{ }^{2} / 14.2,1135 \\
\text { (c. } 100 / 120-150 / 180)\end{array}$ \\
\hline Calagorrit(anus) & C. Sempronius Fidus & $\begin{array}{l}\text { T. honorarius }\left(p_{i} \text { H. c.) }\right. \\
{[\operatorname{flam}(\text { en }) p(\text { rov. })]}\end{array}$ & $\begin{array}{l}\text { CIL } \mathrm{II}^{2} / 14.2,1166 \\
\text { (Flavios - s. II) }\end{array}$ \\
\hline Calagu[rri]tana & Sulpic $[i a]$ & T. honorarius post mort. (maritus et filia) & IRAT 33 (s. II) \\
\hline Carthag(iniensis) & Cn. Numisius Modestus & $\begin{array}{l}\text { T. honorarius (p. H. c.) } \\
{[\operatorname{flam}(\text { en }) p(\text { rov. })]}\end{array}$ & $\begin{array}{l}C I L \mathrm{II}^{2} / 14.2,1154 \\
\text { (Antonio Pío) }\end{array}$ \\
\hline Casc(antinus) & C. Granius Sabinus & Fecit t. sepulcralem (libertae, sibi et suis) & $\begin{array}{l}\text { CIL } \mathrm{II}^{2} / 14.3,1299 \text { (s. } \\
\text { II): Casc(anto); cf. } \\
\text { AE 2006, 606: } \\
\text { [C]ascantinus }\end{array}$ \\
\hline Castulonens(is) & P. Cornelius Verecundus & $\begin{array}{l}\text { T. honorarius (p. H. c.) } \\
{[\operatorname{flam}(e n) p(\text { rov. })]}\end{array}$ & $\begin{array}{l}C I L \mathrm{II}^{2} / 14.2,1130 \\
\text { (c. } 120-150 / 180)\end{array}$ \\
\hline Complu[te]nsis & C. Apu[l]eius Lupus & Fecit t. honorarium (amico) & $\begin{array}{l}\text { IRAT } 9 \\
\text { (Flavios-p.s. II) }\end{array}$ \\
\hline Damanitanus & $\begin{array}{l}\subset \text { Manius } \supset \text { Valerius } \\
\text { Capellianus }\end{array}$ & $\begin{array}{l}\text { T. honorarius (p. H. c.) } \\
{[\text { flam }(\text { en }) \text { R. D. et A. p(rov.)] }}\end{array}$ & $\begin{array}{l}C I L \mathrm{II}^{2} / 14.2,1169 \\
\text { (Antonio Pío) }\end{array}$ \\
\hline
\end{tabular}




\begin{tabular}{|c|c|c|c|}
\hline ORIGO & ANTROPONIMIA & TITVLVS & REFERENCIA \\
\hline Dian'en'sis $^{\prime}$ & [L.] Valerius Propinquus & $\begin{array}{l}\text { T. honorarius (p. H. c.) } \\
\text { [flam (en) R. D. et A. [p]rovinc.] }\end{array}$ & $\begin{array}{l}\text { CIL } \mathrm{II}^{2} / 14.2,1170 \\
(\text { c. } 120-150 / 180)\end{array}$ \\
\hline Edetanus & $\begin{array}{l}\text { M. Valer(ius) Propinquus } \\
\text { Grattius Cerealis }\end{array}$ & $\begin{array}{l}\text { T. honorarius (p. H. c.) } \\
{[\text { flam }(\text { en }) \text { p (rov.)] }}\end{array}$ & $\begin{array}{l}\text { CIL } \mathrm{II}^{2} / 14.2,1171 \\
(c .100)\end{array}$ \\
\hline Flaviaugustanus & L. Aufidius Celer Masculinus & $\begin{array}{l}\text { T. honorarius (res publica sua d. d.) } \\
{[\text { flamen designatus } p \text { (rov.)] }}\end{array}$ & $\begin{array}{l}\text { CIL II'/14.2, } 1117 \\
\text { (c. } 70-150 / 180)\end{array}$ \\
\hline Gerundens(is) & C. Marius Verus & $\begin{array}{l}\text { T. honorarius (p. H. c.) } \\
\text { [flamen provinc.] }\end{array}$ & $\begin{array}{l}\text { CIL II }{ }^{2} / 14.2,1153 \\
\text { (c. } 120-150 / 180)\end{array}$ \\
\hline Gralliensis & M. Sempr(onius) Capito & $\begin{array}{l}\text { T. honorarius (p. H.c.) } \\
{[\text { flam }(\text { en }) p(\text { rov.)] }}\end{array}$ & $\begin{array}{l}\text { CIL II } \mathrm{II}^{2} 14.2,1165 \\
\text { (c. } 120-150 / 180)\end{array}$ \\
\hline Ilerdensis & Atilia Valeriana & T. honorarius (libertus, liberta) & $\begin{array}{l}\text { CIL II } \mathrm{I}^{2} / 14.3,1295 \\
\text { (Adriano) }\end{array}$ \\
\hline Hilerdensis (sic) & Baebia Ursina & T. sepulcralis (maritus) & $\begin{array}{l}\text { CIL II }{ }^{2} / 14.3,1241 \\
\text { (s. II) }\end{array}$ \\
\hline $\begin{array}{l}\text { Iuliobrigens }[\text { is }] \\
\text { ex gente Cantabrorum }\end{array}$ & C. Annius Flavus & $\begin{array}{l}\text { T. honorarius (p. H. c.) [ob causas } \\
\text { utilitatesque publicas... defensas] }\end{array}$ & $\begin{array}{l}\text { CIL } \mathrm{II}^{2} / 14.2,1191 \\
\left.\text { (c. p. o } 1^{\mathrm{a}} \mathrm{m} . \mathrm{s} . \mathrm{II}\right)\end{array}$ \\
\hline Cantabr(us) Iuliobrig(ensis) & Q. Porcius Vetustinus & $\begin{array}{l}\text { T. honorarius (pos. p. H. c.) } \\
\text { [pos. [flam (en) p(rov.)]] }\end{array}$ & $\begin{array}{l}\text { CIL II } \mathrm{I}^{2} / 14.2,1162 \\
\text { (Trajano o Adriano) }\end{array}$ \\
\hline $\operatorname{Lancien}[s(i s)]$ & $\begin{array}{l}\text { L. Iunius Maro } \\
\text { Aem[il(ius)] Paternus }\end{array}$ & $\begin{array}{l}\text { T. honorarius (p. H. c.) } \\
{[\text { flamen Augustalis p (rov.)] }}\end{array}$ & $\begin{array}{l}\text { CIL } \mathrm{II}^{2} / 14.2,1146 \\
\text { (c. 120-150) }\end{array}$ \\
\hline Libisosanus & $\begin{array}{l}\text { C. Vibius Porcianus } \\
\text { Quintius Italicianus }\end{array}$ & $\begin{array}{l}\text { T. honorarius (p. H. c.) } \\
{[\text { flam }(\text { en }) \text { p (rov.)] }}\end{array}$ & $\begin{array}{l}\text { CIL } \mathrm{II}^{2} / 14.2,1173 \\
\text { (Antonio Pío) }\end{array}$ \\
\hline Limicus & M. Flavius Sabinus & $\begin{array}{l}\text { T. honorarius (p. H. c.) } \\
\text { [flamen p }(\text { rov.)] }\end{array}$ & $\begin{array}{l}\text { CIL II } \mathrm{I}^{2} / 14.2,1136 \\
(c .70-150 / 180)\end{array}$ \\
\hline Osicerde(n)sis & Porcia Materna & $\begin{array}{l}\text { T. honorarius (L. Numisius Montanus } \\
\text { uxori, cf. sup.) } \\
{[[f f(\text { aminica) }] \text { p(rov.) }}\end{array}$ & $\begin{array}{l}\text { CIL } \mathrm{II}^{2} / 14.2,1182 \\
\text { (Antonino Pío) }\end{array}$ \\
\hline Palent(ina) & Lic(inia) Flaccilla & Fecit t. honorarium (sorori) & $\begin{array}{l}\text { CIL II } / 14.3,1303 \\
\text { (c. f. s. II o p. s. III) }\end{array}$ \\
\hline Palmensis & L. Aufidius Secundus & $\begin{array}{l}\text { T. honorarius (p. H. c.) } \\
{[\text { flam }(e n) p(\text { rov. })]}\end{array}$ & $\begin{array}{l}\text { CIL II'/14.2, } 1118 \\
\text { (c. } 120-150)\end{array}$ \\
\hline Pallmensis & L. Clodius Ingenuus & $\begin{array}{l}\text { T. honorarius (p. H. c.) } \\
{[\text { flamen R. D. et A. p(rov.)] }}\end{array}$ & $\begin{array}{l}\text { CIL II } \mathrm{II}^{2} 14.2,1127 \\
\text { (c. } 120-150 / 180)\end{array}$ \\
\hline $\begin{array}{l}\text { Balearicus Palmensis } \\
\text { et Guiuntanus }\end{array}$ & Cn. Gavius Amethystus & $\begin{array}{l}\text { T. honorarius (p. H. c.) } \\
\text { [[flamen p }(\text { rov.)]] }\end{array}$ & $\begin{array}{l}\text { CIL } \mathrm{II}^{2} / 14.2,1140 \\
\text { (c. } 150-180)\end{array}$ \\
\hline Pompaelonensis & G. Cornelius Valens & $\begin{array}{l}\text { T. honorarius }(p . \text { H. c.) } \\
\text { [ob legationem censualem gratuitam] }\end{array}$ & $\begin{array}{l}\text { CIL II }{ }^{2} / 14.2,1193 \\
\text { (c. 173) }\end{array}$ \\
\hline
\end{tabular}




\begin{tabular}{|c|c|c|c|}
\hline ORIGO & ANTROPONIMIA & TITVLVS & REFERENCIA \\
\hline Pompaelonensis (cognom.) & $\begin{array}{l}\text { Cn. Pompeius } \\
\text { Pompaelonensis }\end{array}$ & $\begin{array}{l}\text { T. honorarius (p. H. c.) } \\
{[\text { flam }(e n) p(\text { rov. })]}\end{array}$ & $\begin{array}{l}\text { CIL II }{ }^{2} / 14.2,1157 \\
(c .70-150 / 180)\end{array}$ \\
\hline Pompaelonensis & Sempronia Placida & $\begin{array}{l}\text { T. honorarius (maritus consensu } \\
\text { concili(i) p. H. c.) } \\
\text { [flaminica](uxor Cornelii Valentis, } \\
\text { cf. sup.)] }\end{array}$ & $\begin{array}{l}\text { CIL } \mathrm{II}^{2} / 14.2,1184 \\
(c .170-175)\end{array}$ \\
\hline Saet[abitanus] & Q. Fab[ius] M[---] & $\begin{array}{l}\text { T. honorarius (p. H. c.) } \\
{[\text { flam }(\text { en })[p(\text { rov. })]]}\end{array}$ & $\begin{array}{l}\text { CIL II } \mathrm{I}^{2} / 14.2,1133 \\
\text { (c. 125-138) }\end{array}$ \\
\hline Saguntinus & Q. Caecilius Rufinus & $\begin{array}{l}\text { T. honorarius }(\text { p. } \text { H. c.) } \\
\text { [ob legationem gratuitam] }\end{array}$ & $\begin{array}{l}\text { CIL II²/14.2, } 1192 \\
\text { (Adriano) }\end{array}$ \\
\hline Saguntinus & M. Fabius Maximus & $\begin{array}{l}\text { T. honorarius (p. H. c.) } \\
{[\text { flam }(e n) p(\text { rov. })]}\end{array}$ & $\begin{array}{l}\text { CIL II } \mathrm{I}^{2} / 14.2,1134 \\
\text { (c. } 70-180)\end{array}$ \\
\hline Segobrigensis & L. Grattius Glaucus & $\begin{array}{l}\text { T. honorarius (amicus) } \\
\text { [flam }(\text { en }) p(\text { rov.)] }\end{array}$ & $\begin{array}{l}\text { CIL } \mathrm{II}^{2} / 14.2,1142 \\
(c .70-180)\end{array}$ \\
\hline Segobrilglensis & C. Iulius Pila & $\begin{array}{l}\text { T. honorarius (p. H. c.) } \\
\text { [flamen R. D. et A. prov.] }\end{array}$ & $\begin{array}{l}\text { CIL } \mathrm{II}^{2} / 14.2,1144 \\
\text { (c. } 70-150 / 180)\end{array}$ \\
\hline Segontinus & C. Atilius Crassus & $\begin{array}{l}\text { T. honorarius (p. H.c.) } \\
\text { [flam (en) prov.] }\end{array}$ & $\begin{array}{l}\text { CIL II } \mathrm{I}^{2} / 14.2,1116 \\
\text { (c. 120-150) }\end{array}$ \\
\hline Toletanus & Cn. Pompeius Fructus & $\begin{array}{l}\text { T. sepulcralis (heres) } \\
{[b(\text { ene)f(iciarius) } \operatorname{co}(n) s(\text { ularis })]}\end{array}$ & $\begin{array}{l}\text { CIL II }{ }^{2} / 14.2,1056 \\
\left(2^{2} \text { m. s. II-p. s. III }\right)\end{array}$ \\
\hline Tritiens(is) Magal(lensis) & T. Mamilius Praesens & $\begin{array}{l}\text { T. honorarius (p. H. c.) } \\
{[\text { flamen p }(\text { rov.)] }}\end{array}$ & $\begin{array}{l}\text { CIL II } \mathrm{I}^{2} / 14.2,1150 \\
\text { (c. 161-180) }\end{array}$ \\
\hline Uxamens(is) & Ambirodacus & $\begin{array}{l}\text { Fecit t. sepulcralem (memoriae libertae } \\
\text { et uxoris) }\end{array}$ & $\begin{array}{l}\text { CIL } \mathrm{II}^{2} / 14.3,1266 \\
\text { (in dubio: s. I/ s. II) }\end{array}$ \\
\hline $\operatorname{Vergiliens(is)}$ & $\begin{array}{l}\text { M. Cornelius Marcius } \\
\text { Severus }\end{array}$ & $\begin{array}{l}\text { T. honorarius (p. H. c.) } \\
{[\text { flam }(e n) p(\text { rov. })]}\end{array}$ & $\begin{array}{l}\text { CIL II } \mathrm{II}^{2} / 14.2,1129 \\
\text { (c. } 120-150 / 180)\end{array}$ \\
\hline Viminaciensis & Pom(peia) Paterna & T. honorarius (soror) & $\begin{array}{l}\text { CIL II } \mathrm{II}^{2} / 14.3,1303 \\
\text { (c. f. s. II-p. s. III) }\end{array}$ \\
\hline
\end{tabular}

\section{2. Hispani Tarraconenses en Tarraco: mención de la origo y de la proce- dencia del conventus}

\begin{tabular}{|c|c|c|c|}
\hline ORIGO + EX CONVENTVS & ANTROPONIMIA & TITVLVS & REFERENCIA \\
\hline $\begin{array}{l}\text { Aquifl(aviensis) } \\
\text { ex convent(u) Bracaraug(ustano) }\end{array}$ & C. Ceraecius Fuscus & $\begin{array}{l}\text { T. honorarius (p. H. c.) } \\
{[[\text { flamen p(rov.)]] }}\end{array}$ & $\begin{array}{l}C I L \mathrm{II}^{2} / 14.2,1126 \\
(c .150-180)\end{array}$ \\
\hline $\begin{array}{l}\text { Adovus } \\
\text { ex } \subset \text { conventu } \supset \text { Lucen[sium] }\end{array}$ & M. Iulius [Se]renianus & $\begin{array}{l}\text { T. honorarius (p. H. c.) } \\
[\text { fll(amen) } p(\text { rov. })]]\end{array}$ & $\begin{array}{l}\text { González, Ortiz de } \\
\text { Urbina (2015); } \\
\text { CIL II }{ }^{2} / 14.2,1145: \\
\text { Ado[pti]vus } \\
\text { (c. } 195-211)\end{array}$ \\
\hline
\end{tabular}




\begin{tabular}{|c|c|c|c|}
\hline ORIGO + EX CONVENTUS & ANTROPONIMIA & TITVLVS & REFERENCIA \\
\hline $\begin{array}{l}\text { Amocensis } \\
\text { Cluniens(is) ex gente Cantabro(rum) }\end{array}$ & Paetinia Paterna & $\begin{array}{l}\text { T. honorarius (maritus consent. p. H. c.) } \\
\text { [flaminic(a) p(rov.)] }\end{array}$ & $\begin{array}{l}\text { CIL II } \mathrm{I}^{2} / 14.2,1180 \\
\text { (c. m. s. II o post.) }\end{array}$ \\
\hline $\begin{array}{l}\text { Intercatiensis } \\
\text { ex gen[te] [V]accaeorum Cluniensis }\end{array}$ & L. Anto[ni]us Modestus & $\begin{array}{l}\text { T. honorarius (p. H. c.) } \\
{[\text { fl(amen) } p(\text { rov.)] }}\end{array}$ & $\begin{array}{l}\text { CIL II } \mathrm{II}^{2} / 14.2,1114 \\
\text { (c. m. s. II o post.) }\end{array}$ \\
\hline $\begin{array}{l}\text { ex conven[t(u)] Caesar(augustano) } \\
\text { Ercavic(ensis) }\end{array}$ & M. Calp[ur(nius)] Lu[pus] & $\begin{array}{l}\text { T. honorarius (p. H. c.) } \\
{[[\text { flam }(e n)] \text { p(rov.)] }}\end{array}$ & $\begin{array}{l}\text { CIL II } \mathrm{II}^{2} 14.2,1125 \\
\text { (c. } 120 / 150-180)\end{array}$ \\
\hline $\begin{array}{l}\text { ex } \sqsubset \text { conventu } \supset \text { Caesaraug(ustano) } \\
\text { Karensis }\end{array}$ & $\begin{array}{l}\text { Postumia Nepotiana } \\
\text { sive Marcellina }\end{array}$ & $\begin{array}{l}\text { T. honorarius (p. H. c.) } \\
\text { [flaminica] }\end{array}$ & $\begin{array}{l}\text { CIL II } \mathrm{I}^{2} / 14.2,1183 \\
(c .150-180)\end{array}$ \\
\hline $\begin{array}{l}\text { Alabensis } \\
\text { ex } \sqsubset \text { conventu } \supset \text { Carthag(iniensi) }\end{array}$ & L. Caecilius ' ${ }^{\top}$ 'aecianus ? & $\begin{array}{l}\text { T. honorarius (p. H. c.) } \\
\text { [flamen p prov.)] }\end{array}$ & $\begin{array}{l}\text { CIL II } \mathrm{II}^{2} / 14.2,1121 \\
(c .150-180)\end{array}$ \\
\hline $\begin{array}{l}\text { ex conven[tu] Carthag(iniensi) } \\
\text { Attace[nsis] }\end{array}$ & L. Aemilius Paulus & $\begin{array}{l}\text { T. honorarius (p. H. c.) } \\
{[\text { flame }[n] p(\text { rov.) })}\end{array}$ & $\begin{array}{l}\text { CIL II } \mathrm{II}^{2} / 14.2,1111 \\
(c .120-150)\end{array}$ \\
\hline $\begin{array}{l}\text { Segobrig(ensis) } \\
\text { exடconventu Carthag(iniensi) }\end{array}$ & Val(eria) Fida & $\begin{array}{l}\text { T. honorarius (p. H.c.) } \\
\text { [flaminica] }\end{array}$ & $\begin{array}{l}\text { CIL II } 2 / 14.2,1185 \\
(c .150-180)\end{array}$ \\
\hline
\end{tabular}

\section{3. Hispani Tarraconenses en Tarraco: mención de la procedencia del conventus}

\begin{tabular}{|c|c|c|c|}
\hline EX CONVENTV & ANTROPONIMIA & TITVLVS & REFERENCIA \\
\hline ex conventu Bracaro & T. Geminius Philippus & T. sepulcralis (neptis) & $\begin{array}{l}\text { CIL II }{ }^{2} / 14.3,1298 \\
\text { (c. m. s. I o post.) }\end{array}$ \\
\hline ex $\sqsubset$ conventu $\supset$ Bracaraug(ustano) & M. Ulpius Reburrus & $\begin{array}{l}\text { T. honorarius }(p . \text { H. c.) } \\
{[\text { flam }(e n) p(\text { rov. })]}\end{array}$ & $\begin{array}{l}C I L \mathrm{II}^{2} / 14.2,1168 \\
\text { (c. } 150-180)\end{array}$ \\
\hline ex $\sqsubset$ conventu $\supset$ Bracaraug(ustano) & Pomp(eia?) Maximina & $\begin{array}{l}\text { T. honorarius (p. H.c.) } \\
{[\operatorname{flam}(\text { inica })]}\end{array}$ & $\begin{array}{l}C I L \mathrm{II}^{2} / 14.2,1181 \\
\text { (c. } 150-180)\end{array}$ \\
\hline ex [conv(entu)] Bracara[ug(ustano)] & [C.? Iulius] Saturninus & T. sepulcralis (soror) & $\begin{array}{l}\text { CIL II }{ }^{2} / 14.3,1302 \\
\text { (s. III) }\end{array}$ \\
\hline ex $\sqsubset$ conventu $\supset$ Lucen[sium] & C. Virius Fronto & $\begin{array}{l}\text { T. honorarius (ex decreto } \\
\text { concilii p. H. c.) } \\
{\left[\text { flam }(e n){ }^{\prime} p^{j}(\text { rov. })\right]}\end{array}$ & $\begin{array}{l}\text { CIL } \mathrm{II}^{2} / 14.2,1174 \\
\text { (c. } 150-180)\end{array}$ \\
\hline ex $\sqsubset$ conventu $\supset$ Cluniens $(i)$ & Aurelia Marcellin(a) & $\begin{array}{l}\text { T. honorarius [cives } \\
{[\text { T]arrac(onenses)] }} \\
\text { flaminica] }\end{array}$ & $\begin{array}{l}\text { CIL } \mathrm{II}^{2} / 14.2,1177 \\
\text { (c. f. s. II o p. s. III) }\end{array}$ \\
\hline
\end{tabular}

\section{4. Hispani Tarraconenses (posibles) en Tarraco: mención de la domus}

\begin{tabular}{|l|l|l|l|}
\hline \multicolumn{2}{|c|}{ DOMVS } & \multicolumn{1}{c|}{ TNTROPONIMIA } & \multicolumn{1}{c|}{ REFERENCIA } \\
\hline Auso & Pom(peius?) Fae[---] & $\begin{array}{l}\text { T. sepulcralis } \\
\text { [mercandi causa }]\end{array}$ & $\begin{array}{l}\text { CIL II } \text { I }^{2} 14.3,1290 \\
\text { (s. II o s. III) } \\
\text { cf. Haley, 1986, p. } \\
\text { 280, n. 608: (domo) } \\
\text { Ausone }\end{array}$ \\
\hline Selg'isama Brasaca & & $\begin{array}{l}\text { CIL II'/14.2, 1067 } \\
\text { (f. s. I-s. II) }\end{array}$ \\
\hline
\end{tabular}


II. 5. Hispani Tarraconenses fuera de Tarraco: mención de la natio

\begin{tabular}{|l|l|l|l|}
\hline \multicolumn{2}{|c|}{ NATIO } & ANTROPONIMIA & \multicolumn{2}{c|}{ REFERENCIA } \\
\hline Tarracone & Corbulo & T. sepulcralis & $\begin{array}{l}\text { Roma } \\
\text { CIL II }{ }^{2} / 14, \text { E } 1 \\
\text { (c. post. s. II) }\end{array}$ \\
\hline Hispan(us) Tarraconensis & L. Aur(elius) Silvinus & T. sepulcralis & $\begin{array}{l}\text { Carnuntum } \\
\text { (Pannonia sup. }) \\
\text { CIL II }{ }^{2} / 14, \text { E } 4 \\
\text { (c. f. s. II) }\end{array}$ \\
\hline
\end{tabular}

